\title{
Individual and combined soy isoflavones exert differential effects on metastatic cancer progression
}

\author{
Michelle M. Martínez-Montemayor • Elisa Otero-Franqui • \\ Joel Martinez • Alina De La Mota-Peynado • \\ Luis A. Cubano $\cdot$ Suranganie Dharmawardhane
}

Received: 5 February 2010/Accepted: 12 May 2010/Published online: 2 June 2010

(c) The Author(s) 2010. This article is published with open access at Springerlink.com

\begin{abstract}
To investigate the effects soy isoflavones in established cancers, the role of genistein, daidzein, and combined soy isoflavones was studied on progression of subcutaneous tumors in nude mice created from green fluorescent protein (GFP) tagged-MDA-MB-435 cells. Following tumor establishment, mice were gavaged with vehicle or genistein or daidzein at $10 \mathrm{mg} / \mathrm{kg}$ body weight (BW) or a combination of genistein $(10 \mathrm{mg} / \mathrm{kg} \mathrm{BW})$, daidzein $(9 \mathrm{mg} / \mathrm{kg} \mathrm{BW})$, and glycitein $(1 \mathrm{mg} / \mathrm{kg} \mathrm{BW})$ three times per week. Tumor progression was quantified by whole body fluorescence image analysis followed by microscopic image analysis of excised organs for metastases. Results show that daidzein increased while genistein decreased mammary tumor growth by 38 and 33\% respectively, compared to vehicle. Daidzein increased lung and heart metastases while genistein decreased bone and liver metastases. Combined soy isoflavones did not affect primary tumor growth but increased metastasis to all organs tested, which include lung, liver, heart, kidney, and bones. Phosphoinositide-3-kinase (PI3-K) pathway real time PCR array analysis and western blotting of excised tumors demonstrate that genistein significantly downregulated
\end{abstract}

Electronic supplementary material The online version of this article (doi:10.1007/s10585-010-9336-x) contains supplementary material, which is available to authorized users.

E. Otero-Franqui · S. Dharmawardhane $(\bowtie)$

Department of Biochemistry, School of Medicine,

University of Puerto Rico, Medical Sciences Campus,

San Juan, PR 00969, USA

e-mail: su.d@upr.edu

M. M. Martínez-Montemayor - E. Otero-Franqui - J. Martinez · A. De La Mota-Peynado - L. A. Cubano - S. Dharmawardhane Department of Biochemistry and Cell Biology, School of Medicine, Universidad Central del Caribe, Bayamón, PR, USA
10/84 genes, including the Rho GTPases RHOA, RACl, and $C D C 42$ and their effector $P A K 1$. Daidzein significantly upregulated $9 / 84$ genes that regulate proliferation and protein synthesis including EIF4G1, eIF4E, and survivin protein levels. Combined soy treatment significantly increased gene and protein levels of EIF4E and decreased TIRAP gene expression. Differential regulation of Rho GTPases, initiation factors, and survivin may account for the disparate responses of breast cancers to genistein and daidzein diets. This study indicates that consumption of soy foods may increase metastasis.

Keywords Genistein · Daidzein · Glycitein · Cancer metastasis $\cdot$ Soy isoflavones

\section{Introduction}

Breast cancer is the most commonly diagnosed form of cancer in women 40-55 years of age and is a major cause of cancer deaths [1]. Metastatic breast cancer, where the cancer cells spread using motile mechanisms and establish tumors at distant vital sites, is much harder to eradicate and is often the cause of death from breast cancer. Interest in soy isoflavones has been fueled by studies that demonstrate a lower incidence of menopausal symptoms, osteoporosis, cardiovascular disease, breast and endometrial cancers in Asian women who have a diet rich in soy products [2, 3]. The anti-breast cancer effects of soy foods have been shown to be effective at early stages of carcinogenesis and most studies have focused on prevention of breast cancer risk by soy isoflavones $[4,5]$. Moreover, their benefits as chemopreventives for breast cancer or as substitutes for hormone replacement therapies (HRT) remain controversial $[2,6,7]$. The effect of soy foods on established cancers 
have not been systematically examined and the effect of soy consumption for women at high risk for breast cancer or survivors of breast cancer are not known [2]. The present study was designed to understand the impact of soy foods on established breast cancer.

Soy isoflavones are present in soy foods as aglycones where genistein, daidzein, and glycitein make up 50\%, $40 \%$, and $10 \%$, respectively, of the total soybean isoflavones [8]. Isoflavones are structurally similar to estrogen and genistein and daidzein, but not glycitein, can bind to and transactivate estrogen receptors (ER) with a higher affinity for $\operatorname{ER} \beta[9,10]$. The chemopreventive cytotoxic effects of genistein have been shown for both ER $(+)$ and ER (-) breast cancer cell lines including the MDA-MB-435 cells used in this study [11-13]. In vivo, genistein has also been shown to inhibit cancer initiation of chemically-induced rodent models $[14,15]$. A study that used a lung metastatic variant of MDA-MB-435 reported that genistein $(750 \mu \mathrm{g} / \mathrm{g}$ mouse chow) administered prior to mammary tumor cell inoculation or following surgical removal of the primary mammary tumor resulted in reduced lung metastases [16]. Moreover, recent data indicate that genistein inhibits invasion, metastasis, and angiogenesis in vitro and in vivo in a number of cancers including breast cancer [16-19]. However, other studies have shown that soy isoflavones, particularly genistein, increase the growth of MCF-7 human breast cancer cells and tumors in ovariectomized nude mice and metastatic progression of prostate cancer [20, 21]. These contradictory results may be due to the fact that the hormonal milieu can be an important factor in determining the in vivo effects of isoflavones, where reports indicate that genistein and daidzein can block physiological estrogeninduced rat pituitary tumor cell growth [22].

At the molecular level, soy isoflavones have estrogenic/ antiestrogenic, antioxidant and anti-angiogenic activities and may affect cancer due to their effects on apoptosis, cell cycle progression, growth, and differentiation. In addition to attenuating cell growth via inhibition of ER, genistein has also been shown to block growth factor- and cytokinestimulated proliferation of cells. Genistein affects cellular function via inhibition of enzymes required to convert androgens to $\mathrm{E}_{2}$ (17 beta-steroid oxidoreductase and aromatases), tyrosine protein kinases, cytochrome p450 enzymes, and cycloxygenase 2 [6, 23, 24]. Genistein also modulates the activity of topoisomerase II, enzymes involved in phosphoinositide (PI) turnover, transforming growth factor (TGF)- $\beta$ signaling cascades, ER levels, growth factors and their receptor levels, mitogen activated protein kinases (MAPK) and p38 MAPK activity, urokinase-type plasminogen activator (uPA) and matrix metalloproteinases (MMP) secretion, NF- $\kappa \mathrm{B}$, focal adhesion kinase (FAK), Akt and WNT signaling pathways, and DNA methylation [17, 19, 24-33].
The specific effects of daidzein or glycitein on signaling pathways have not been investigated as comprehensively as with genistein. At high concentrations, daidzein exerts anti proliferative effects by the generation of reactive oxygen species (ROS), disruption of mitochondrial transmembrane potential; downregulation of $\mathrm{Bcl}-2$, growth factors, cytokines, cyclin dependent kinases, and DNA checkpoint proteins; and upregulation of Bax and cyclin dependent kinase inhibitors [25, 34]. One study using $10 \mu \mathrm{M}$ glycitein has shown inhibitory effects on cell growth and induction of apoptosis by reduced Bcl-2/Bax ratio in MCF-7 breast cancer cells [10]. Interestingly, most of the studies detailing the effects of individual soy isoflavones focus on their effects on non-metastatic cell lines and the effect of soy isoflavones at multiple stages of the metastatic cascade remain to be elucidated [35]. The present study was conducted to test the effects of soy isoflavones using the MDA-MB-435 cell line as a model for a highly invasive and metastatic cancer. Future studies will involve a more comprehensive investigation of the signaling pathways regulated by genistein, daidzein, and glycitein.

The origin of the MDA-MB-435 cell line has been questioned by comparative genomic hybridization studies that report MDA-MB-435 and M14 melanoma to be identical cell lines [36]. However, as reviewed in [37], both cell lines may be of MDA-MB-435 breast cancer origin rather than of melanoma origin due to the following rationale. The MDA-MB-435 cell line was isolated from a pleural effusion of a female patient with breast cancer and still has two $\mathrm{X}$ chromosomes; expresses milk proteins and lipids; and when transfected with the nm23 metastasis suppressor gene, MDA-MB-435 cells show the morphologic features of normal breast epithelial cells, including acinus formation in three-dimensional culture [38]. Moreover, MDA-MB-435 cells have been extensively used to investigate metastasis from the mammary fat pad and remains as one of few models available for experimental metastasis in nude mice [39, 40]. As with most metastatic breast cancers, this cell line is ER (-), and genistein is known to inhibit growth and induce apoptosis of MDAMB-435 cells [13].

In the present study, we used a green fluorescent protein (GFP)-tagged bone metastatic variant of the MDA-MB-435 cell line (described in [39]) to investigate the effect of dietary isoflavones (genistein and daidzein) individually and in the combination found in soy foods (genistein $50 \%$, daidzein $40 \%$, and glycitein $10 \%$ ) on established breast cancer growth and metastasis. Herein, we report differential effects where genistein decreased while daidzein increased primary tumor growth, metastasis, and expression of genes and proteins involved with tumor progression. Combined soy isoflavones did not affect primary 
tumor growth but increased metastasis. Therefore, the results of this study indicate that consumption of soy products may have differential and complex effects on breast cancer progression and metastasis to different organs.

\section{Materials and methods}

Cell culture

A bone metastatic variant of GFP-MDA-MB-435 cell line was used (gift of Dr. Danny Welch, The University of Alabama at Birmingham) and cultured as described in [39]. The development of this cell line and its usefulness as a model for experimental metastasis is described in [41].

\section{Animals}

Female athymic nu/nu mice, 5 week old (Charles River Laboratories, Wilmington, MA) were maintained and cared for as in [42, 43]. The mice received autoclaved AIN 76-A phytoestrogen-free diet (Tek Global, Harlan Teklad, Madison, WI) and water ad libitum. This protocol was approved by the Universidad Central del Caribe IACUC.

\section{Tumor model}

GFP-MDA-MB-435 cells $\left(\sim 1 \times 10^{6}\right)$ in Matrigel (BD Biosciences, San Jose, CA) were injected into the mammary fat pad under isofluorane inhalation as described in [43, 44]. After tumor establishment (1 week post-inoculation), the animals were randomly divided into control and experimental groups.

\section{Diet administration}

Study 1 . Nude mice ( $n=10$ /group) were orally gavaged with vehicle ( $90 \%$ corn oil, $10 \%$ ethanol), $10 \mathrm{mg} / \mathrm{kg} \mathrm{BW}$ genistein, or $10 \mathrm{mg} / \mathrm{kg} \mathrm{BW}$ daidzein in a $100 \mu \mathrm{l}$ volume three times per week. Study 2. Nude mice ( $n=10$ /group) were orally gavaged with vehicle or soy isoflavones (10 mg/kg-BW genistein, $9 \mathrm{mg} / \mathrm{kg}-\mathrm{BW}$ daidzein, and $1 \mathrm{mg} / \mathrm{kg}-\mathrm{BW}$ glycitein) in a $100 \mu \mathrm{l}$ volume three times per week. Treatments continued until sacrifice at $\mathrm{d} 78$.

For all treatments, some early deaths occurred due to metastatic burden. Therefore, only 8 mice/group remained for the final analysis.

Whole body fluorescence image analysis

The mice were imaged following tumor establishment, and twice per week thereafter, until d 77 (one $\mathrm{d}$ prior to sacrifice at $\mathrm{d}$ 78). Tumor progression was monitored by fluorescence image analysis and quantified as in [42]. Relative tumor area was calculated as the fluorescence intensity of each tumor on day of imaging relative to the fluorescence intensity of the same tumor on d 01 of diet administration using ImageJ software (National Institutes of Health, Bethesda, MD).

Analysis of metastases

Following sacrifice, lungs, kidneys, liver, femurs, and hearts were excised and immediately stored in liquid nitrogen. Stored organs were thawed and analyzed using an Olympus MVX10 fluorescence stereoscope and an Olympus DP71 microscope digital camera (Olympus America, Inc, Melville, NY) as in [43].

Statistical analysis

Statistical analyses were done using Microsoft excel. $P$ values were determined using Students $t$ test and values $\leq 0.05$ were considered significant.

\section{Real time RT-PCR analysis}

Solid primary tumors ( $n=3 /$ treatment group) were excised, cut in half, and immediately stored in "RNAlater" (Ambion, Austin, TX) for analysis as described in [43]. Total RNA extraction and gDNA elimination was performed using the Qiagen RNeasy Kit (Qiagen, Valencia, CA). RNA $(0.5 \mu \mathrm{g})$ was used to synthesize cDNA using C$03 \mathrm{RT}^{2}$ First Strand Kit (SA Biosciences, Frederick, MD), and gene expression profiles were investigated using the human PI3-K/Akt signaling Pathway (PAHS-058A) $\mathrm{RT}^{2}$ Profiler $^{\mathrm{TM}}$ PCR arrays (SA Biosciences, Frederick, MD). The spreadsheets, gene tables, and template formulas included with the PCR array package were used to calculate relative changes in gene expression as described in [43].

\section{Western blot analysis}

Flash frozen primary tumors were lysed using a homogenizer (Brinkmann Polytron, Mississauga, ONT, Canada) in lysis buffer (10\% SDS, $10 \%$ sodium deoxycholate, $1 \%$ Triton-X 100, 1\% Igepal, and protease and phosphatase inhibitors) and quantified using the Precision Red protein assay kit (Cytoskeleton, Inc. Denver, CO). Equal total protein amounts were resolved on SDS-PAGE gels and Western blotted using anti-RhoA, anti-Rac1, anti-Cdc42, and anti-PAK1 (Santa Cruz Biotechnology, Inc., Santa Cruz, CA), anti-GFP (Abcam, Cambridge, MA), antiactin (Sigma-Aldrich Comp., St. Louis, MO), anti-eIF4G and anti-eIF4E (Epitomics, Inc., Burlingame, CA), and 
anti-survivin (Cell Signaling Technology, Inc., Danvers, MA) antibodies. The integrated density of positive bands was quantified using ImageJ software. Quantification of tumor proteins was ensured by normalizing the integrated densities of positive bands for all antibodies to the integrated density of the same tumor lysate western blotted for GFP or actin.

\section{Results}

Effect of soy isoflavones on primary mammary tumor growth

Study 1: effects of major soy isoflavones, genistein and daidzein, on primary mammary tumor growth

To test the effect of genistein and daidzein on metastatic breast cancer progression in vivo, we established mammary fat pad tumors from GFP-MDA-MB-435 cancer cells as in [44]. One week following cell inoculation, mice were gavaged with vehicle, $10 \mathrm{mg} / \mathrm{kg} \mathrm{BW}$ genistein, or $10 \mathrm{mg} / \mathrm{kg} \mathrm{BW}$ daidzein thrice/week. These diets were selected to represent high levels of soy consumption, that were correlated with reduced breast cancer risk [45] and as per similar studies in rodents that demonstrated reduced tumor progression with genistein [46, 47]. Tumor growth remained linear during the course of the study. After 40 days, genistein-treated mice demonstrated reduced tumor growth while daidzein-treated mice demonstrated accelerated tumor growth compared to vehicle (Fig. 1a). Similar to a study that showed a trend in reduced MDA-MB-435 mammary tumor volume in response to dietary genistein [16], we report decreased tumor growth from mice on the genistein diet compared to vehicle controls. Both fluorescence images and weights show that daidzein significantly increased $(P<0.05)$ mammary tumor growth by $38 \%$ and genistein inhibited $(P<0.05)$ mammary tumor growth by $33 \%$ compared to controls (Fig. 1b, c).

\section{Study 2: effects of combined soy isoflavones on primary mammary tumor growth}

Since individual treatments of genistein or daidzein produced clearly disparate effects on mammary tumor growth, we performed a second study to investigate the effects of a combined diet of genistein, daidzein, and glycitein, the major soy isoflavones in the ratio commonly found in fermented soy foods. Treatment with combined soy isoflavones resulted in a similar response as vehicle treatment in primary tumor growth (Fig. 1a). This data on the effect of combined soy isoflavones on ER (-) mammary tumor growth is similar to a previous study with ER $(+)$ mammary

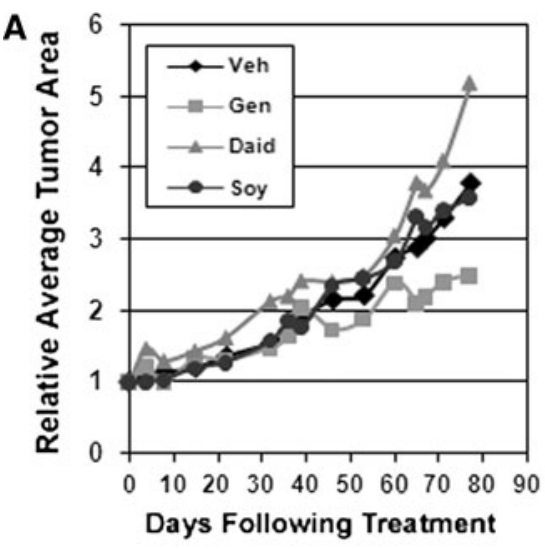

B

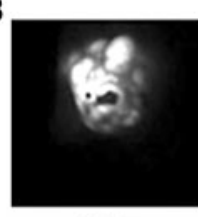

Veh

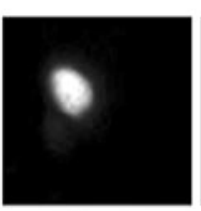

Gen

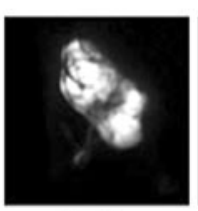

Daid

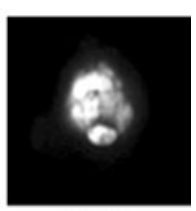

Soy

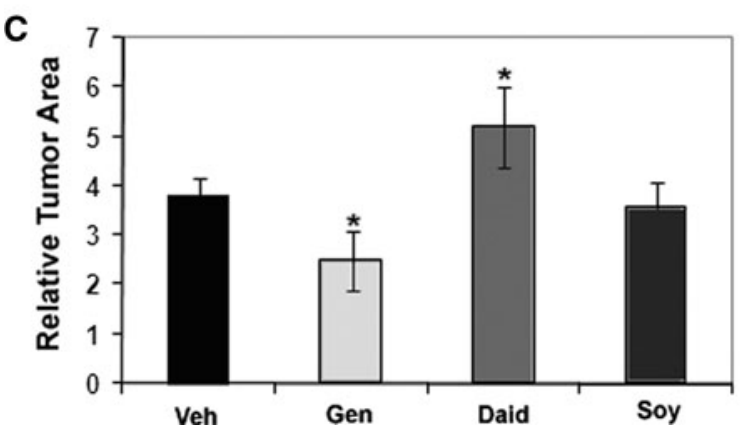

Fig. 1 Effect of soy isoflavones on the growth of MDA-MB-435 mammary fat pad tumors. One week following injection of MDA-MB-435 cells, mice (10/treatment) were fed vehicle (Veh), $10 \mathrm{mg} / \mathrm{kg}-\mathrm{BW}$ genistein (Gen), or daidzein (Daid), or soy isoflavones (10 mg/kg-BW genistein, $9 \mathrm{mg} / \mathrm{kg}-\mathrm{BW}$ daidzein, and $1 \mathrm{mg} / \mathrm{kg}-\mathrm{BW}$ glycitein) $3 \times$ a week. Whole body fluorescence images were acquired $2 \times$ a week. a Average relative tumor area with days post injection, calculated as the area of fluorescence on each day of imaging as a function of the fluorescence intensity of the same tumor on d 01 . b Representative digital images of GFP-MDA-MB-435 tumors following vehicle, genistein, or daidzein diets at d 77. c Average mammary tumor growth as quantified from digital images acquired on $\mathrm{d} 77$, made relative to same tumor image on $\mathrm{d} 01$. Values are mean \pm SEM $(n=8)$. Asterisk denotes statistical significance at $P<0.05$ compared to vehicle control

tumor models that reported no effect of soy isoflavone extract on mammary tumor growth in nude mice [48].

Effect of soy isoflavones on metastasis

Study 1: effects of major soy isoflavones, genistein and daidzein, on metastasis

To investigate the effect of soy isoflavones on metastasis of established carcinomas, the metastatic foci in lung, bone, 
Fig. 2 Effect of genistein and daidzein on metastasis.

a Images of representative lungs and fluorescence image analysis of lungs from mice following vehicle genistein, or daidzein treatment. The average area of fluorescent metastatic foci was calculated from excised lungs after vehicle, genistein, or daidzein treatment.

b Fluorescence image analysis of hearts from mice following vehicle, genistein, or daidzein. c Fluorescence image analysis of bones from mice following vehicle genistein, or daidzein. d Fluorescence image analysis of livers from mice following vehicle genistein, or daidzein. Average area or integrated density of fluorescent metastatic foci/mouse \pm SEM for $n=8 /$ treatment is shown. Asterisk denotes statistical significance $(P<0.05)$ compared to vehicle controls. e The percentage of mice with metastases for each organ (bone, heart, kidney, liver, lung) after vehicle, genistein, or daidzein treatment, as detected from fluorescence images $(n=8)$
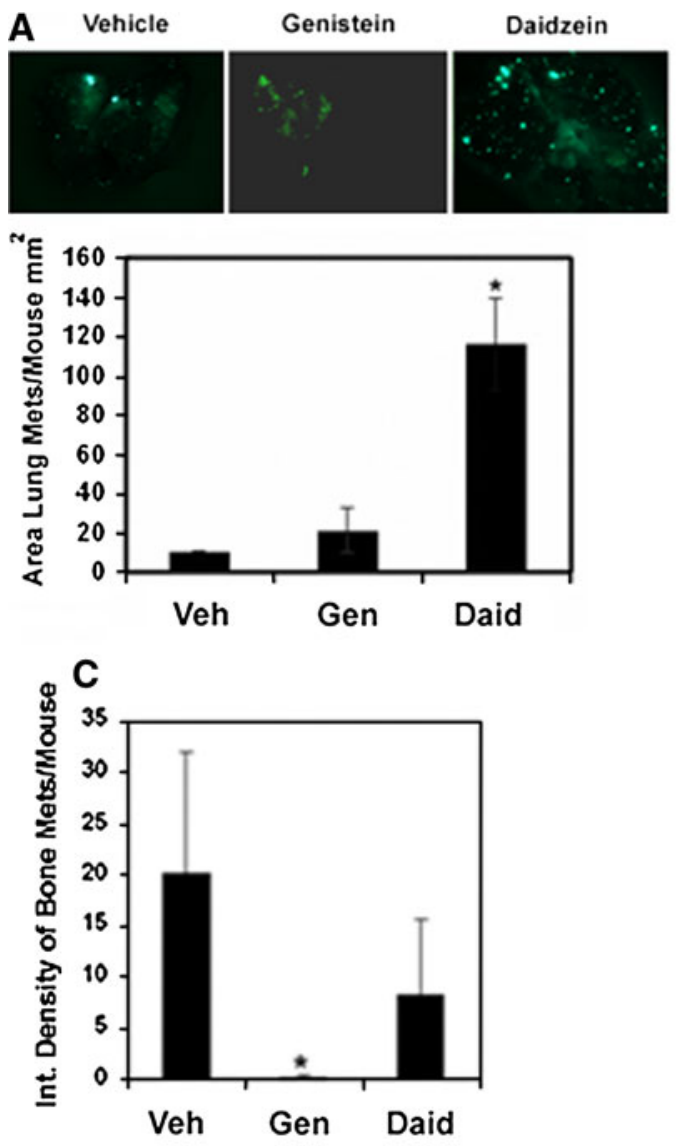

E

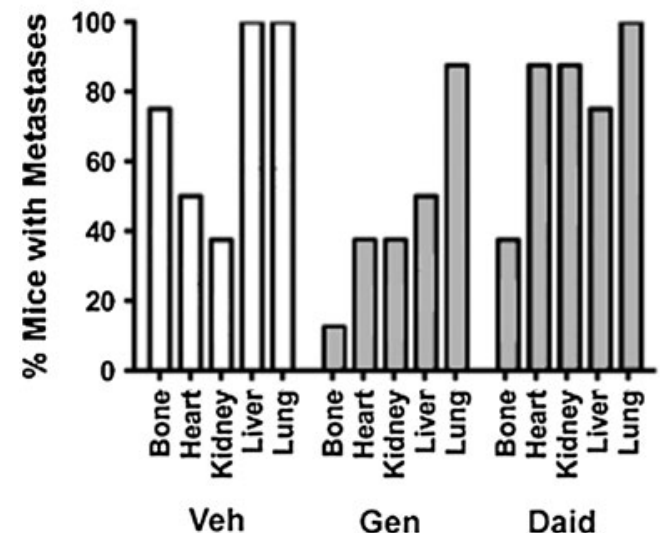

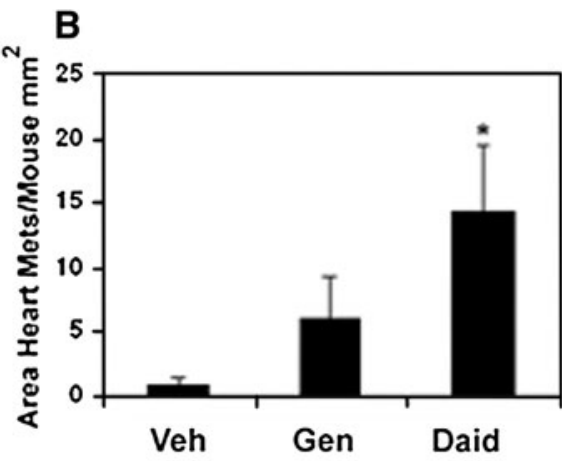

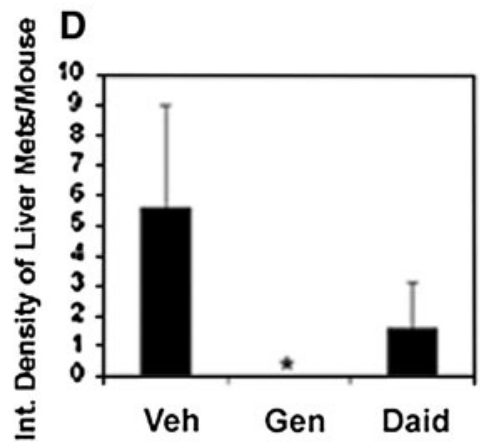

liver, heart, and kidney were analyzed. Whole body image analysis of mice at the time of sacrifice demonstrated that $37.5 \%$ of vehicle or daidzein-fed mice demonstrated easily detectable lymph node metastases while only $25 \%$ of genistein fed mice demonstrated lymph node metastases, although these findings were not statistically significant when compared to the vehicle treated mice (data not shown). Metastatic lesions in other excised organs were imaged using a fluorescence stereoscope. As shown in the examples of lung images in Figs. 2a and 3a, fluorescent images were digitally acquired and used for quantification of metastatic efficiency. Unlike studies that report only the number of mice with metastases at an organ site by random histopathology analysis, our comprehensive fluorescence image analysis allowed the quantification of the total number of metastatic foci per organ as well as area and integrated density of metastatic foci.

Even though the number of mice with lung metastases following genistein were slightly reduced compared to vehicle controls (Fig. 2e), as has been reported before by 
histopathology of lung metastases [16], the total area of fluorescent lesions in the lungs from genistein-treated mice was not statistically significant from controls. Lungs from daidzein-treated mice presented with increased number and area of metastatic lesions with an average of 74 metastatic foci/lung compared to 35 metastatic foci/lung from vehicle-treated mice. The lung metastases from daidzein treated mice were larger than the foci from vehicle treated mice with a statistically significant 12 -fold increase in area of fluorescence $(P<0.05$, Fig. 2a).

Similarly, daidzein treatment exhibited more heart metastases than vehicle or genistein treatments. Heart metastases were observed from $50 \%$ of vehicle, $37.5 \%$ of genistein, and $87.5 \%$ of daidzein treated mice (Fig. 2e). Vehicle or genistein treated mice demonstrated an average of 2 metastatic foci/heart while daidzein resulted in an average of 4.75 metastatic foci/heart. Daidzein treatment demonstrated a 14-fold significant increase in both area and integrated density of heart metastases compared to vehicle $(P<0.03$, Fig. 2b).

In the kidneys, $37.5 \%$ of vehicle or genistein-treated mice and $87 \%$ of daidzein-treated mice presented with metastases (Fig. 2e). Vehicle treatment resulted in an average area of kidney metastasis/mouse of $11.6 \pm 7.1 \mathrm{~mm}^{2}$ while the mice from the genistein treatment demonstrated an average area of $4.9 \pm 1.7 \mathrm{~mm}^{2}$ and daidzein treatment resulted in an average area of $18.9 \pm 9.7 \mathrm{~mm}^{2}$. However, both the changes in area or integrated density of metastatic foci in the kidney in response to genistein or daidzein were not significant when compared to vehicle controls (data not shown). Overall our data demonstrates a lung and heart metastases promoting role for daidzein in ER $(-)$ cancers.

In vehicle controls, $75 \%$ of mice presented with bone metastases with an average of $\sim 6$ metastatic foci/femur with metastases. Only $12.5 \%$ of the genistein-treated and $37.5 \%$ of daidzein-treated mice presented with bone metastases (Fig. 2e). This dramatic decrease in bone metastases in genistein-treated mice was statistically significant $(P<0.05)$, while the bone metastatic response to daidzein was not statistically significant when compared to vehicle controls (Fig. 2c). For liver metastases, all of the vehicle-treated mice demonstrated liver metastases at an average of 29 metastatic foci/liver. From the genistein treatment, $50 \%$ mice presented with liver metastases at an average of 3 metastatic foci/liver and $75 \%$ of daidzeintreated mice demonstrated liver metastases with an average of 12.5 metastatic foci/liver (Fig. 2e). Genistein significantly decreased the average integrated density of liver metastases/mouse by $500 \%$ compared to vehicle controls $(P<0.05)$. The observed decrease in liver metastatic efficiency in response to daidzein was not statistically significant (Fig. 2d). Therefore, dietary treatment with genistein specifically decreased bone and liver metastases.

\section{Study 2: effects of soy isoflavones on metastasis}

The effect of combined soy (genistein:daidzein:glycitein, 5:4:1) treatment on established mammary fat pad tumors was tested in two independent experiments that showed similar results. Since the nude mouse litters as well as the passage and amount of cells used were different for Study 1 (comparison of vehicle, genistein, or daidzein diets) and Study 2 (comparison of vehicle with soy isoflavone combination, genistein, daidzein, and glycitein), the results were analyzed separately and compared with the vehicle treatments for that study.

As shown in Fig. 3, both vehicle and soy-treated groups demonstrated lung metastases in a majority of the mice. Lungs from soy isoflavone-treated mice presented with increased number and area of metastatic lesions with an average of 154 metastatic foci/lung compared to 31 metastatic foci/lung from vehicle-treated mice. The average numbers of metastatic foci/lung (35 and 31) are comparable for the vehicle-treated mice from both Study 1 and Study 2 . The increased number and area of lung metastases in the soy-treated mice resulted in a 36-fold statistically significant increase in integrated density of fluorescence $(P<0.05$, Fig. 3a, f).

Vehicle treated mice did not demonstrate any heart metastases while treatment with soy isoflavones resulted in $50 \%$ of the mice showing heart metastases with an average of 6.5 metastatic foci/heart and an average integrated density of 1.9 (Fig. 3b). In vehicle controls, 20\% of mice presented with bone metastases with an average of $\sim 1$ metastatic lesion/femur with metastases. Following soy isoflavone treatment, $50 \%$ of mice presented with bone metastases with an average of 44 metastatic foci/femur and a 14-fold significant increase in integrated density $(P<0.05$, Fig. 3c). For liver metastases, $50 \%$ of the vehicle-treated mice and $87.5 \%$ of soy-treated mice demonstrated fluorescent metastatic foci where the vehicle treated mice demonstrated an average of 10 metastatic foci/liver while the soy treated mice presented with 169 metastatic foci/liver with a fivefold statistically significant increase in integrated density compared to vehicle $(P<0.05$, Fig. 3d). Similarly, kidney metastases were also significantly increased by the soy treatment where only $20 \%$ of vehicle treated mice demonstrated 2 metastatic foci/kidney while soy isoflavone treatment resulted in $37.5 \%$ of mice with kidney metastases demonstrating 20 metastatic foci/kidney and a $\sim 25$-fold increase in average integrated density $(P<0.05$, Fig. 3e). These results indicate that although combined dietary soy isoflavones do not affect primary tumor size, consumption of 

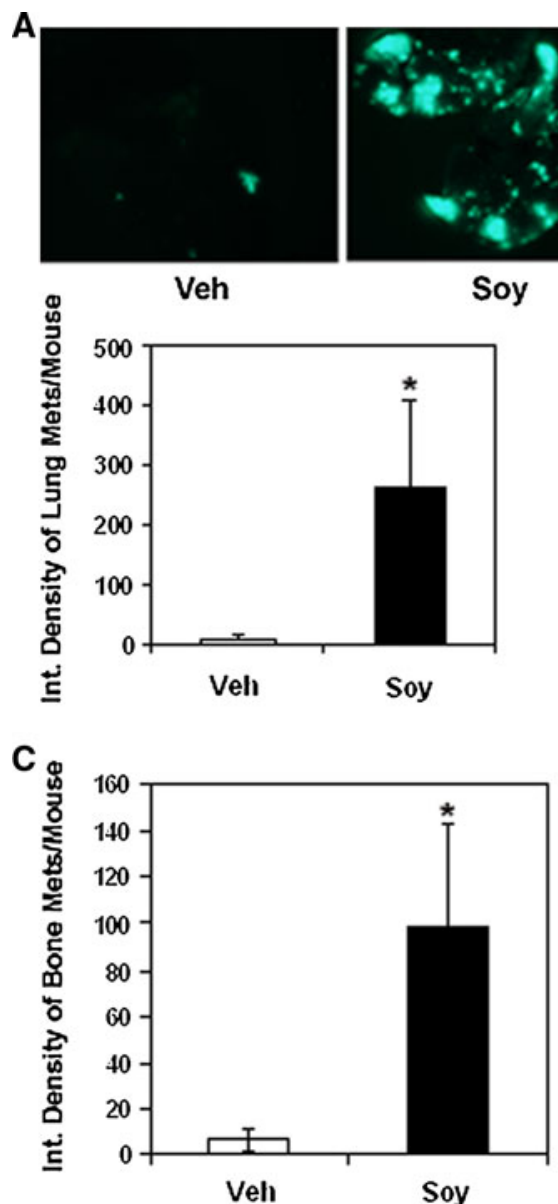

E

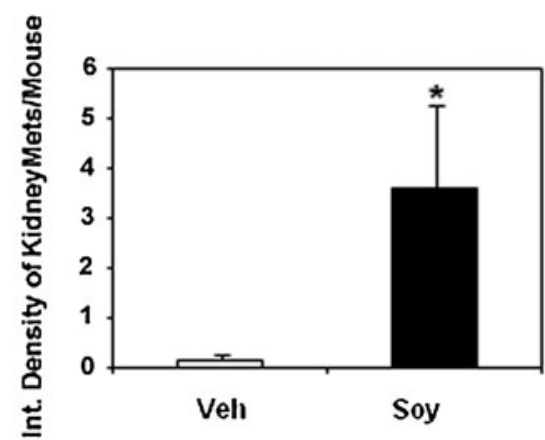

Fig. 3 Effect of soy isoflavones on metastasis. a Images of representative lungs and fluorescence image analysis of lungs from mice following vehicle or soy isoflavones treatment. The average area of fluorescent metastatic foci was calculated from excised lungs after vehicle or soy isoflavone (genistein:daidzein:glycitein, 5:4:1 ratio) treatment (images of representative lungs are shown). b Fluorescence image analysis of hearts from mice following vehicle or soy isoflavone treatment. c Fluorescence image analysis of bones from mice following vehicle or soy isoflavone treatment. d Fluorescence
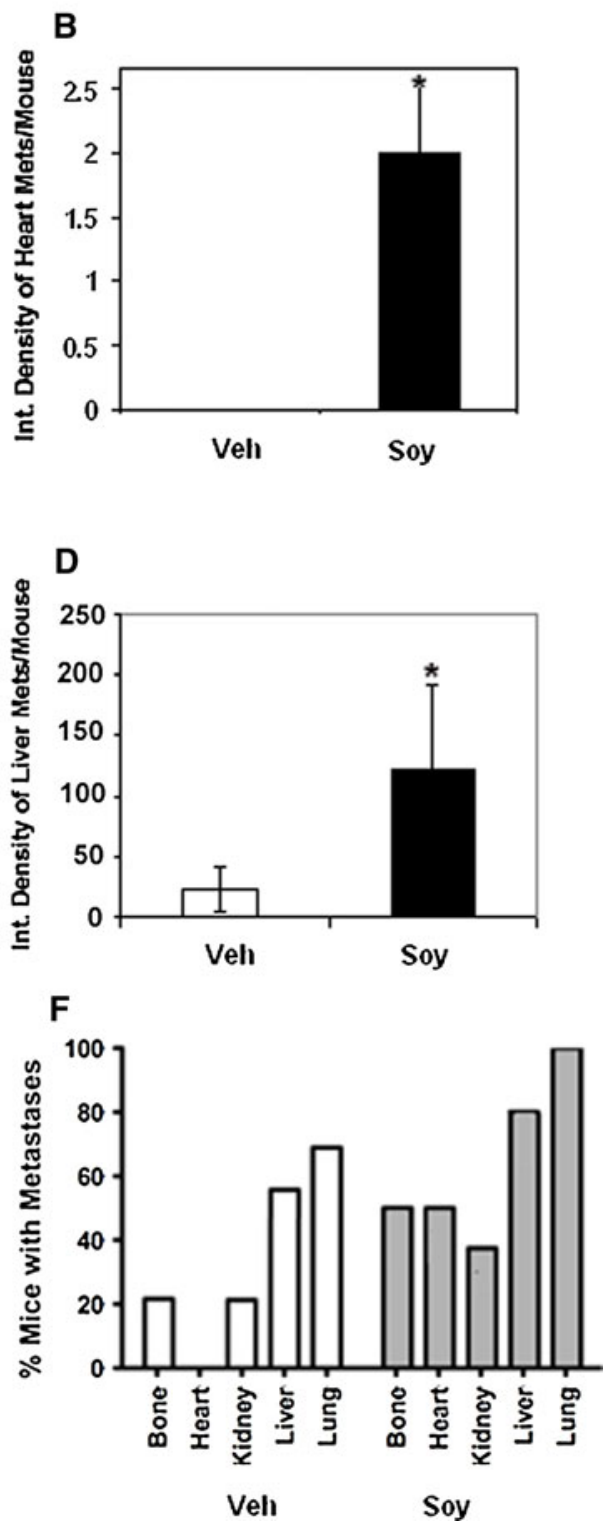

image analysis of livers from mice following vehicle or soy isoflavone treatment. e Fluorescence image analysis of kidneys from mice following vehicle or soy isoflavone treatment. Integrated density of fluorescent metastatic foci/mouse \pm SEM for $n=8 /$ treatment is shown. Asterisk denotes statistical significance $(P<0.05)$ compared to vehicle controls. $\mathbf{f}$ The percentage of mice with metastases for each organ (bone, heart, kidney, liver, lung) after soy isoflavone treatment, as detected from fluorescence images $(n=8)$ 
soy can significantly increase metastasis to all distant organs examined.

Effect of soy isoflavones on expression of metastasispromoting molecules

\section{Effect of soy isoflavones on gene expression}

Since many of the members of the PI3 kinase/Akt pathway have been implicated in cancer survival, invasion, and thus, metastasis [49, 50], the differences in gene expression in primary tumors following dietary treatments were determined using PI3-K real time PCR arrays. Gene expression of tumors from vehicle, genistein, daidzein, or combined soy treated mice were individually assessed using the $2^{(-\Delta \mathrm{Ct})}$ formula by comparing their relative gene expression to reference genes (Fig. 4). Table 1 shows genes with a $-1.3 \geq 1.3$-fold change and statistical significance $(P<0.05)$ compared to controls.

\section{Study 1}

Compared to vehicle, genistein significantly dowregulated 10/84 genes (12\%) and daidzein upregulated 9/84 (11\%) genes, consistent with decreased mammary tumor growth by genistein and increase by daidzein. These numbers are consistent with the predicted value under the null hypothesis since $\sim 100$ genes were studied, the expected number with $P$-values $<0.05$ would be $\sim 5$. Genistein downregulated Ras/mitogen activated protein kinase (MAPK) pathway: $M A P K-1.3$-fold, $P=0.06$ ), GRB2, and RASA1 (Ras GTPase activating protein $)(P<0.05)$ and cell survival (AKT1) genes, while daidzein significantly increased Ras/ MAPK pathway and cell cycle progression regulators: GRB2, MAPK, JUN, CCND1 (cyclin D1), CTNNB1 (beta catenin), and IRSI (insulin receptor substrate 1). Genistein decreased $P A B P C 1$ (poly(A) binding protein) and daidzein increased EIF4G1 (eukaryotic initiation factor F4G1) expression implicating differential protein translational regulation of mammary tumor growth by soy isoflavones. Genistein also downregulated genes involved with invasion and metastasis such as RHOA, RAC1, CDC42, and PAK1 (p21/Cdc42/Rac1-activated kinase 1).

\section{Study 2}

The combined soy isoflavones treatment did not show such dramatic changes in expression of genes involved in the PI3-K/Akt pathway, and only demonstrated a single gene upregulated (EIF4E) and a single gene downregulated $(T I R A P)$ in a statistically significant manner (Fig. 4). A number of genes that were downregulated by genistein

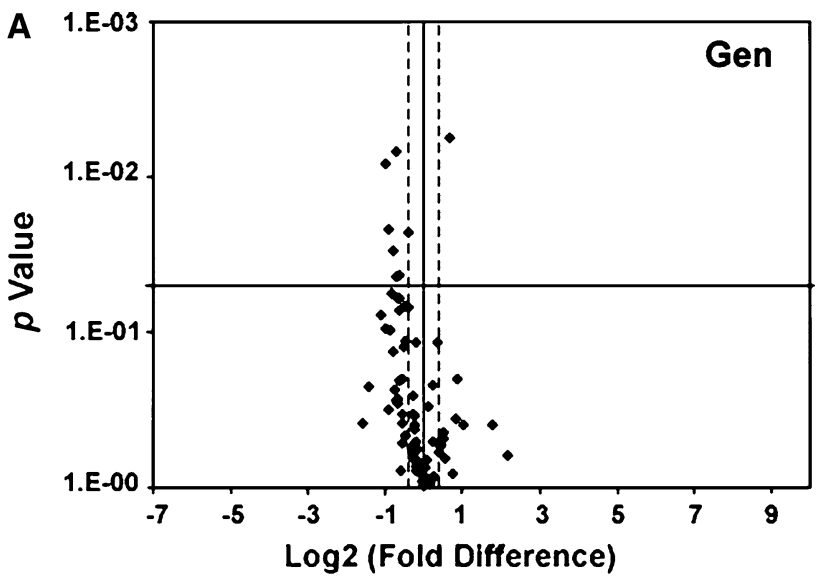

B

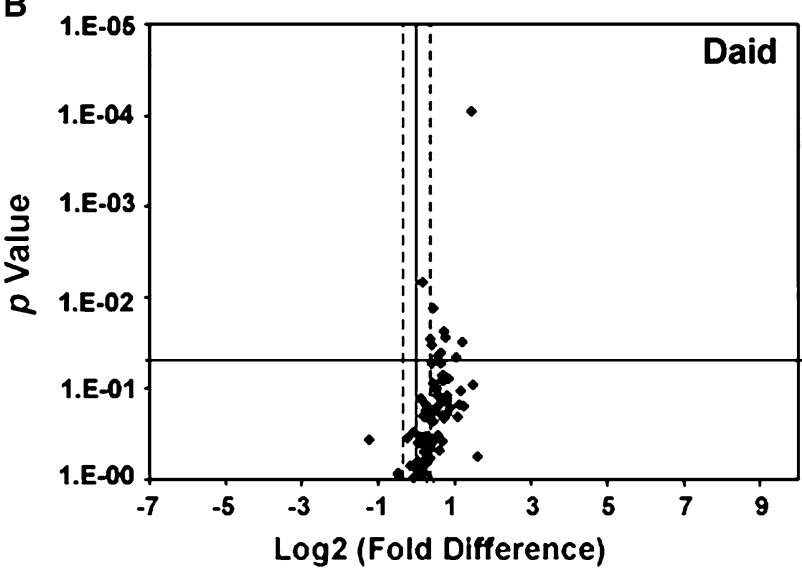

C

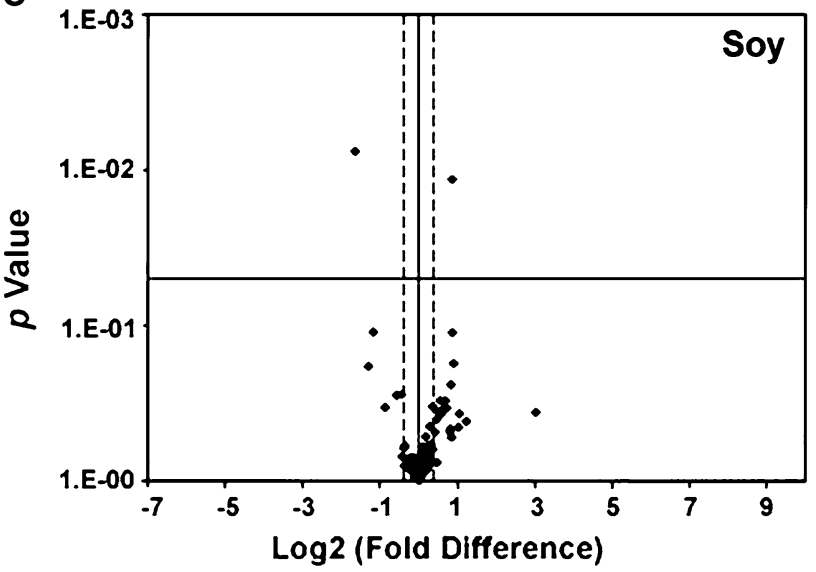

Fig. 4 Effect of dietary soy isoflavones on PI3-K pathway gene expression. Total RNA was extracted from mammary tumors excised from mice that received vehicle, genistein, daidzein, or soy isoflavone combination (genistein, daidzein, glycitein) diets. $\mathrm{RT}^{2}$ PCR array designed to profile the expression of PI3-K pathway-specific genes was used, according to manufacturer's instructions (SA Biosciences). Volcano plots show a genistein; $\mathbf{b}$ daidzein; $\mathbf{c}$ soy combination effects on gene expression analyzed at $-1.3 \geq 1.3 \log _{2}$-fold change (dashed line). Down-regulated genes are to the left of the vertical black line while up-regulated genes are to the right. Statistically significant regulated genes are above the horizontal black line at $P<0.05$ $(n=3)$ 
Table 1 Effect of soy isoflavones on expression of PI3-kinase pathway genes

\begin{tabular}{|c|c|c|c|}
\hline \multirow[t]{2}{*}{ Gene symbol—complete name } & \multicolumn{3}{|c|}{ Fold change, $P$ value } \\
\hline & Genistein & Daidzein & Soy combination ${ }^{\mathrm{a}}$ \\
\hline$A K T 1-\mathrm{v}$-akt murine thymoma viral oncogene homolog 1 & $-1.32,0.02$ & & \\
\hline$C C N D 1-$ Cyclin D1 & & $1.31,0.05$ & \\
\hline CDC42-Cell division cycle 42 (GTP binding protein) & $-1.54,0.04$ & & \\
\hline CTNNB1-Catenin (cadherin-associated protein), beta 1 & & $1.68,0.03$ & \\
\hline EIF $4 E$-Eukaryotic translation initiation factor $4 \mathrm{E}$ & & & $1.82,0.01$ \\
\hline EIF4G1-Eukaryotic translation initiation factor 4 gamma 1 & & $2.29,0.03$ & \\
\hline GRB2-Growth factor receptor-bound protein 2 & $-1.64,0.007$ & $1.50,0.04$ & \\
\hline GSK3B - Glycogen synthase kinase 3 beta & & $1.63,0.02$ & \\
\hline IRAKI-Interleukin-1 receptor associated kinase & $1.60,0.006$ & $2.71,0.0001$ & \\
\hline IRS1-Insulin receptor substrate 1 & & $2.05,0.04$ & \\
\hline$J U N$-Jun oncogene & & $1.54,0.04$ & \\
\hline$M A P K 1$-Mitogen-activated protein kinase 1 & & $1.31,0.03$ & \\
\hline$P A B P C 1$-Poly(A) binding protein & $-1.65,0.04$ & & \\
\hline$P A K 1-\mathrm{p} 21$ protein $(\mathrm{Cdc} 42 / \mathrm{Rac})$-activated kinase 1 & $-2.01,0.008$ & & \\
\hline$R A C 1$-Ras-related $\mathrm{C} 3$ botulinum toxin substrate 1 & $-1.73,0.03$ & & \\
\hline$R A S A 1$-RAS p21 protein activator (GTPase activating protein) & $-1.88,0.02$ & & \\
\hline RHOA—Ras homolog gene family, member A & $-1.78,0.05$ & & \\
\hline TIRAP-Toll-interleukin 1 receptor (TIR) domain containing adaptor protein & & & $-3.11,0.008$ \\
\hline
\end{tabular}

Only genes that demonstrated $-1.3>1.3$-fold difference and $P<0.05$ from $\mathrm{RT}^{2}$ PCR arrays are shown

${ }^{a}$ Soy combination (5:4:1, genistein:daidzein:glycitein)

were also downregulated by the soy treatment as were genes upregulated by daidzein (see Supplemental Information Table 1). Interestingly, the majority of these changes were not statistically significant at a $P$ value $<0.05$. Therefore, combined soy isoflavone treatment may neutralize the effects of the major soy isoflavones genistein and daidzein in regulating the expression of PI3-K pathway genes.

\section{Effect of soy isoflavones on protein expression}

The significant downregulation of gene expression of Rho GTPases $R H O, R A C$, and $C D C 42$, and their downstream effector $P A K$ by genistein treatment was confirmed by western blotting of primary tumor extracts from vehicle, genistein, or daidzein-treated mice. GFP expression was detected to ensure equal protein levels and the source of human breast cancer cells. Genistein treatment resulted in $\sim$ 1.5-2-fold reduced gene and protein expression of Pak1, Cdc42, Rac1, and RhoA (Fig. 5a). Daidzein treatment did not show significant differences in gene expression of Rho GTPases and their downstream effector $P A K 1$, but demonstrated a fivefold significant increase in Rac1 protein expression compared to vehicle controls (Fig. 5b). This novel result indicates that the elevation of Rac levels by daidzein is post-transcriptionally regulated while downregulation of Rac, Rho, Cdc42, and Pak1 expression by genistein is transcriptionally regulated. Confirming the results of the PCR array, combined soy isoflavone treatment did not significantly change Rho, Rac, Cdc42, or Pak levels in primary tumors (data not shown).

Since the PCR array data showed elevated EIF4G levels, we determined whether daidzein treated primary tumors demonstrated a parallel increase in eIF4G protein levels. As shown in Fig. 6, compared to vehicle, genistein treatment did not significantly change eIF4G or eIF4E levels but dietary daidzein significantly increased eIF4G levels by 3.5 -fold and eIF4E levels by sevenfold in primary mammary tumors $(P<0.05)$ (Fig. 6a). The combined soy treatment did not significantly change eIF4G but demonstrated a significant 2.5-fold upregulation of eIF4E levels in the tumors (Fig. 6b). Since, eIF4E is known to selectively target the expression of mRNAs that regulate cancer cell proliferation and survival [51, 52], the expression of survivin, a member of the inhibitors of apoptosis (IAP) family [53], was monitored in tumors from mice following vehicle or soy isoflavones. In these experiments, the integrated density of bands positive for eIF4G, eIF4E, or survivin were normalized with the density for actin or GFP and the fold changes were found to be similar. As shown in Fig. 6a, $\mathrm{b}$, relative expression of actin for each mouse tumor remained unchanged. Actin levels were used as a control for these results because studies have shown that mRNAs with long structured 5'untranslated regions (UTR) such as 

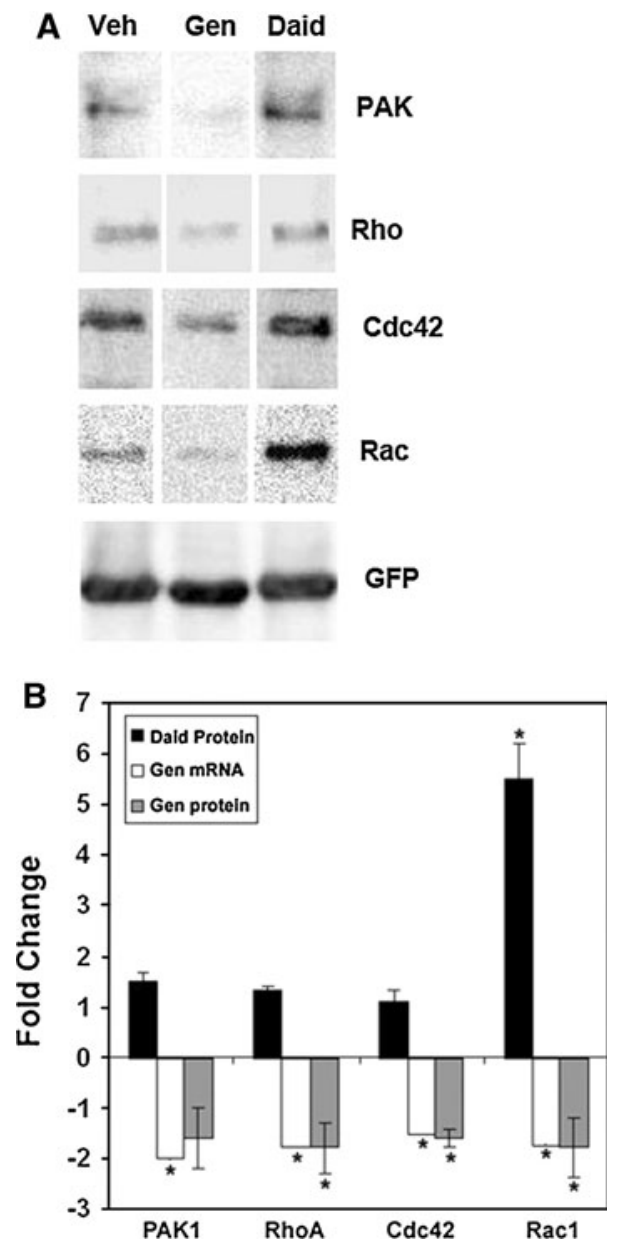

Fig. 5 Effect of genistein and daidzein on gene and protein expression of Rho GTPases and Pak1. Total lysates of mammary tumors were western blotted with anti Pak1, RhoA, Rac, Cdc42, or GFP antibodies. a Representative western blot for tumor extracts from vehicle, genistein or daidzein treatments. b Fold changes in Rho GTPase gene or protein expression for tumors from genistein- or daidzein-treated mice compared to vehicle. $\log _{2}$-fold changes in gene expression were calculated from PCR arrays. Fold changes in protein expression were calculated from integrated density of positive bands from western blots. Equal total protein content as well as confirmation of human cancer cells in the mouse tumor extracts was maintained by expressing the integrated density of each band for Pak1, RhoA, Rac1, or Cdc42 as a function of the integrated density of the GFP band from the same tumor extract. Values show mean \pm SEM $(n=6)$. An asterisk indicates statistical significance of $P<0.05$

survivin are dependent on eIF4G and eIF4E availability while genes with short $5^{\prime}$ UTRs such as actin are not sensitive to eIF4 levels $[51,52]$. Results show that genistein significantly inhibited survivin expression in mammary tumors by 1.65 -fold when compared to vehicle controls while daidzein significantly upregulated survivin protein expression by 1.95 -fold $(P<0.05)$ (Fig. $6 \mathrm{c})$. The combined soy isoflavones treatment increased survivin expression by 1.5 -fold but this increase was not statistically significant. Therefore, daidzein may promote cancer
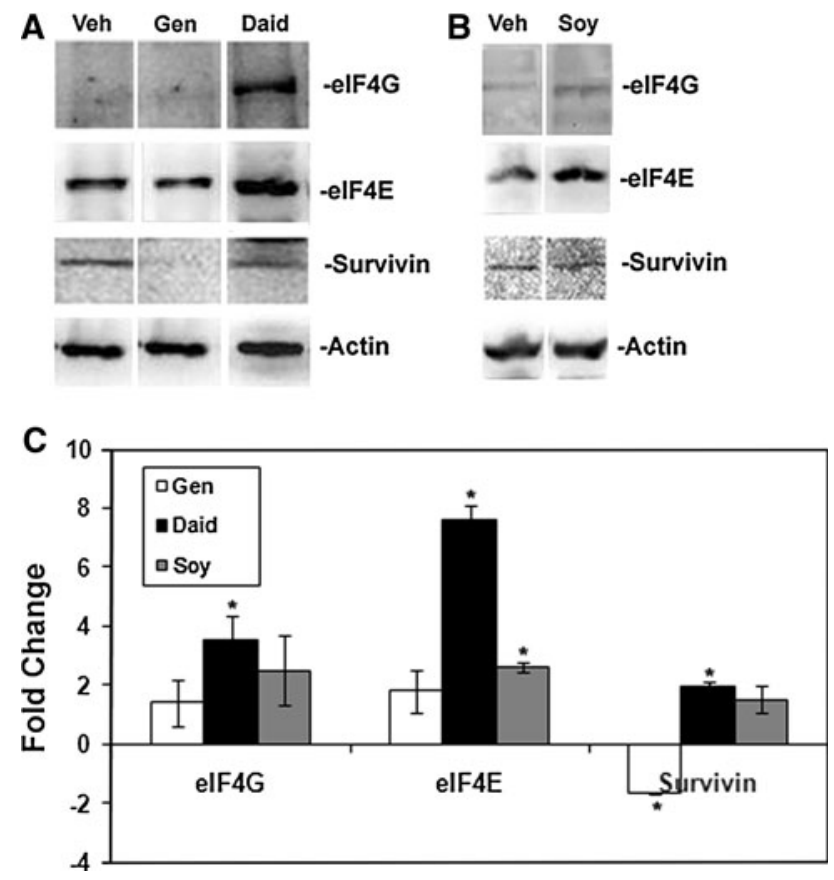

Fig. 6 Effect of soy isoflavones on protein expression. Total lysates of mammary tumors from mice treated with vehicle, genistein, daidzein, or soy (genistein:daidzein:glycitein, 5:4:1 ratio) were western blotted with anti-eIF4G, anti-eIF4E, or anti-survivin antibodies. a Representative western blots for tumor extracts from vehicle, genistein, or daidzein. b Representative western blots for tumor extracts from vehicle, or combined soy treatments. c Fold changes in eIF4G, eIF4E, and survivin protein expression for tumors from genistein, daidzein, or soy treated mice compared to vehicle as calculated from the integrated density of positive bands from western blots and normalized with actin expression. Values show mean \pm SEM $(n=4)$. An asterisk indicates statistical significance of $P<0.05$

progression via increased translation of specific mRNAs relevant for cancer cell survival such as survivin.

\section{Discussion}

An aggressive bone metastatic variant of the MDA-MB435 cancer cell line was used as a model system to investigate the effect of soy isoflavones on mammary cancer progression. To our knowledge, this is the first time that the effects of dietary soy isoflavones were assessed on bone metastases from primary mammary tumors in a nude mouse model. Investigation of the effect of dietary cancer chemopreventives on bone metastasis is important because most breast cancers in humans preferentially metastasize to the bone [54]. Because the MDA-MB-435 cells were inoculated at the mammary fat pad, this strategy enabled the investigation of metastases to a number of distant organs. Our results demonstrate an inhibitory role for genistein and a promoting role for daidzein and combined soy isoflavones in breast cancer progression. Genistein (5,7-dihydroxy-3-(4-hydroxyphenyl) chromen-4-one or 
4',5,7-Trihydroxyisoflavone) and daidzein (7-hydroxy-3(4-hydroxyphenyl) chromen-4-one or 4',7-Dihydroxyisoflavone) are structurally different only in the hydroxyl group in position 5. Glycitein (4',7-dihydroxy-6-methoxyisoflavone) has a methoxy group in position 6 , and as in the case of daidzein, glycitein does not have the hydroxyl group in position 5. Nevertheless, as shown in the present study, this slight structural difference could play a crucial role in the estrogenic/antiestrogenic (or other biological) activities of these compounds.

Isoflavones have short half-lives $(\sim 8 \mathrm{~h})$, and nearly all are excreted within $24 \mathrm{~h}$ after ingestion [55]. Results from a recent report using rats show that genistein can be detected in serum $5 \mathrm{~min}$ post-oral administration [56]. Because of rapid mouse metabolism, a $10 \mathrm{mg} / \mathrm{kg} \mathrm{BW}$ mouse dose can be considered equivalent to $1 \mathrm{mg} / \mathrm{kg} \mathrm{BW}$ in humans (an approximation of a high Asian soy diet). In our studies, isoflavones were administered by gavage three times a week at $10 \mathrm{mg} / \mathrm{kg} \mathrm{BW}$ for individual isoflavones and at $10 \mathrm{mg} / \mathrm{kg}$ BW genistein, $9 \mathrm{mg} / \mathrm{kg}$ BW daidzein, and $1 \mathrm{mg} / \mathrm{kg}$ BW glycitein for combined isoflavones. Thus, the mice received a continuous isoflavone diet. The diet of $10 \mathrm{mg} / \mathrm{kg}-\mathrm{BW}$ genistein in a $\sim 20-25 \mathrm{mg}$ mouse works out to be $0.2 \mathrm{mg}$ genistein/mouse at $\sim 7 \mathrm{mM}$ concentration. Although we did not determine the levels of soy isoflavones in tumor tissue, previous mouse studies have reported isoflavone levels at $1.2 \mathrm{mg} / \mathrm{g}$ tissue daidzein and $6.5 \mathrm{mg} / \mathrm{g}$ tissue for genistein following genistein or soy diets [17]. The plasma concentrations of mice receiving dietary genistein similar to those used in the present study have been reported to be in the range of the plasma concentrations found in humans after soy consumption [33, 57].

We demonstrate an inhibitory role for genistein and a promoting role for daidzein in tumor growth and metastasis. Moreover, combined soy isoflavones (genistein, daidzein, and glycitein) in the ratio found in soy foods did not affect tumor growth at the mammary fat pad but increased metastasis to all organs tested. These results were obtained with high dietary concentrations and the effect of soy isoflavones in our system at low concentrations remain to be tested. Genistein is known to have a biphasic effect on tumor growth and metastasis, where low concentrations are stimulatory and high concentrations are inhibitory [21]. Similar to our results, an inhibitory role for genistein in mammary tumor growth and metastatic progression has been reported for both ER $(+)$ and ER ( - ) breast cancers $[16,58]$, while daidzein was shown to stimulate cell and tumor growth of ER (+) MCF-7 non-metastatic breast cancer cells in ovariectomized nude mice [59]. Moreover, in the ER $\beta$ positive MDA-MB-231 cell line, even though genistein inhibited cell growth at all concentrations tested, dietary genistein did not affect growth of subcutaneous tumors from MDA-MB-231 cells in nude mice [60].
Herein, using the highly metastatic ER (-) MDA-MB-435 cell line to establish mammary fat pad tumors in nude mice, we show that dietary daidzein increased tumor growth and metastatic efficiency indicating that the tumor promoting effect of daidzein is not ER dependent. Dietary genistein and soy phytochemical concentrate have been shown to reduce primary tumor growth and metastasis in bladder and prostate cancer models [17, 33], while other studies have shown that soy isoflavones, particularly genistein, increased the growth of MCF-7 human breast cancer cells and tumors in ovariectomized nude mice and metastatic progression of prostate cancer $[20,21]$. The results shown herein using an ER (-) Her-2 (++) highly metastatic cancer cell line may reflect the role of soy isoflavones on mammary tumor growth and metastases from such aggressive cancers.

Mice that received dietary genistein specifically demonstrated reduced bone and liver metastases in a statistically significant manner indicating a potential site-specific inhibition of extravasation and (or) secondary tumor establishment at these sites. Previous studies have shown that genistein inhibits MMP secretion [13] and cell invasion [26], which may lead to the observed reduction in invasion to distant sites in genistein-treated mice. Unlike previous studies that showed that genistein causes a decrease in lung metastases from the MDA-MB-435 lung metastatic variant and prostate and bladder cancer models $[16,17,33]$, our data did not show a significant difference in lung metastases in response to dietary genistein. This difference in the genistein response maybe due to differences in the protocols, where; (1) we used a bone metastatic variant of the parental MDA-MB-435 cell line, (2) we did not initiate dietary treatments until mammary tumors were established $\left(\sim 0.5 \mathrm{~mm}^{2}\right)$, and (3) we administered genistein at $10 \mathrm{mg} / \mathrm{kg} \mathrm{BW} 3 \times$ a week by direct oral gavage instead of incorporating into the mouse chow. The preventive effects of genistein on metastasis that have also been shown previously using the same (Her-2)++ MDAMB-435 model [16] may be due to the reported inhibitory effects of genistein on Her-2 expression and phosphorylation, thus activation [61]. Future studies will assess the effect of genistein on invasion/metastasis of mammary tumors using a cell line such as MDA-MB-231 that does not overexpress Her-2 or EGFR but exhibits some lung metastasis in the nude mouse model.

We have previously shown that daidzein promoted cell functions relevant for metastasis such as FAK activity, focal adhesion assembly, extension of actin structures that promote cell migration, and cell migration to a greater level than genistein in breast cancer cell lines [62]. The present study expands these observations to show that dietary daidzein promotes lung, and heart metastases compared to vehicle and genistein treatments. Moreover, dietary soy 
isoflavones significantly promoted metastases to all organs evaluated. The significant increased incidence of lung and heart metastases in daidzein and soy isoflavone diets indicate higher incidence of cancer cell intravasation into the blood stream since the heart and lungs are the first organs encountered by invasive cancer cells in blood vessels. Since the increased metastases caused by the daidzein treatment parallels the increased primary tumor growth in response to dietary daidzein, elevated metastatic efficiency of the daidzein-treated mice may reflect the higher numbers of cells that left the primary mammary tumors and invaded into the circulatory system. The genistein treated mice that presented with smaller mammary tumors but did not significantly change lung, heart, or kidney metastases, indicates that metastatic efficiency of genistein-treated mice is not directly correlated with primary mammary tumor size. This observation is also reflected in mice following combined soy isoflavone treatment that did not show changes in primary tumor size. This null effect on primary tumor growth by dietary soy isoflavones may be due to a potential negation of the observed disparate effects of genistein and daidzein on primary tumor growth. However, soy isoflavone treatment increased metastases to all organs indicating that this effect was not dependent on primary mammary tumor size or organ site but a non-specific overall increase in metastatic efficiency by the combined effect of genistein, daidzein, and glycitein at a 5:4:1 ratio. These effects were exemplified in some cases by the clear presence of cancer cells in the gastrointestinal tract of mice after combined soy isoflavones diets (data not shown).

The differential effects of soy isoflavones on mammary tumor progression, i.e. primary tumor growth and metastasis prevention to bone and liver by genistein, increased primary mammary tumor progression and metastasis to the heart and lungs by daidzein, and promotion of metastasis to all organs by combined genistein, daidzein, and glycitein may be due to a number of reasons. (1) Potential concentration-dependent effects of each compound at different organ sites can exist due to unequal distribution of the dietary isoflavones and their metabolites leading to sitespecific effects on the expression of metastasis promoters and suppressors. For instance, a recent study reported that following daidzein consumption, high levels of daidzein and its metabolite equol were found in bone tissue of mice [63]. Thus, levels of daidzein may reach bone tissue in concentrations high enough to be inhibitory even though the decreased trend in metastasis to the bone following daidzein diets was not statistically significant when compared to vehicle controls. Studies using the MCF-7 ER (+) breast cancer cell line have shown that physiological concentrations of genistein induced while pharmacological concentrations of genistein reduced expression of genes that regulate cell cycle progression [56]. Therefore, higher concentrations of genistein at bone and liver may function to specifically inhibit establishment of metastases at these sites. (2) In addition, the soy isoflavones may have differential effects on tumor cell intravasation and extravasation at various organ sites. Currently we are conducting site-specific molecular analysis of the molecular signatures at distant organs following soy isoflavone diets and expect to correlate the changes in signaling molecules with dietary interventions.

The observed tumor and organ site-dependent differences in the effects of daidzein, genistein or combined soy isoflavones may be due to differences in the signaling molecules that are expressed by the tumor cells in response to these compounds. Therefore, gene expression profiles were performed on RNA extracted from excised primary mammary tumors of mice following vehicle or dietary soy isoflavone treatments. Since the major isoflavones found in soy (genistein, daidzein and glycitein) have been shown to regulate cancer cell survival $[10,34,56]$, the present study was conducted to determine the gene expression profiles of PI3-K signaling pathway molecules from primary mammary tumors of mice following dietary genistein, daidzein or soy combination treatments. PI3-K-catalyzed phosphorylation of the conversion of membrane phophatidyl inositol bis phosphate (PIP2) to phosphatidyl inositol 3,4,5phosphate (PIP3) results in the activation of a number of signaling pathways including Akt/mammalian target of rapamycin (mTOR), Ras/MAPK, and FAK/Rac/Cdc42 pathways that can lead to cancer cell survival, proliferation, and invasion $[49,50]$.

Our PCR array data show increases in the expression of a number of genes that regulate cell growth and cell cycle progression and protein translation in response to daidzein while genistein reduced the expression of genes implicated in cell survival, proliferation, and invasion. Moreover, animals that were on the soy combination diet showed an increase in the expression of one gene that regulates protein synthesis, and a decrease in the expression of one gene that is involved in the innate immune system response. However, transcriptional regulation of genes may not indicate post-transcriptional, translational, or post translational control. A recent study reported that genistein increased tumor levels of FAK, p38 MAPK, and heat shock protein (HSP27) but that these proteins were not activated by phosphorylation [33]. Therefore, the reported differences in gene and protein expression may not indicate protein activity and regulation of specific protein activities by soy isoflavones will be the focus of future studies.

Our novel report that in mammary tumors, dietary genistein significantly decreased both gene and protein expression of Rho GTPases (Rho, Rac, and Cdc42) and the downstream effector of Rac and Cdc42, PAK1, are significant for understanding the mechanism by which 
genistein inhibits cancer cell invasion. Rho GTPases are known to promote cancer progression by regulation of actin dynamics, cell-extracellular matrix interactions, cell cycle progression, cell survival, and invasion [64, 65]. At high concentrations, genistein acts as a tyrosine kinase inhibitor and inhibits Rho-dependent focal adhesion assembly and actin cytoskeleton reorganization [66]. The present data indicates that dietary genistein may reduce breast cancer progression via transcriptional regulation of Rho GTPases and PAK.

The reduced $P A B C P$ levels by genistein may also indicate a global decrease in mRNA translation that may account for the reduced expression of all of the proteins that were tested. Other microarray studies have shown that high concentrations of genistein reduced expression of genes that regulate cell cycle progression and increased expression of pro-apoptotic genes [67]. The reduction of $G R B 2$ and MAPK expression by genistein in the mammary tumors may also lead to a decrease in Ras/MAPK activity as seen in previous studies [68]. A recent PCR array study that used human prostate cancer cell lines to determine the effect of genistein and daidzein reported that $40 \mu \mathrm{M}$ genistein or $110 \mu \mathrm{M}$ daidzein was effective at inhibiting cell cycle progression and upregulated cyclin dependent kinase inhibitors and cyclin $\mathrm{H}$ and downregulated cyclin dependent kinases [25]. Our study, that used genistein and daidzein at physiologically relevant concentrations, report that while dietary genistein decreased the expression of $G R B 2$ and $M A P K$, dietary daidzein significantly increased the expression of cell cycle regulators and signaling molecules that promote cell cycle progression (Cyclin D1, $\beta$ catenin, GRB2, MAPK, JUN). Therefore, this data indicates that at dietary concentrations, genistein and daidzein can exert differential effects on genes that regulate cancer cell invasion, survival, and proliferation and thus, contribute to tumor malignancy.

Daidzein treatment did not change gene expression of Rho GTPases or PAK1 in mammary tumors. However, daidzein significantly increased protein expression of Rac, a central regulator of actin cytoskeletal changes during cancer cell invasion [69]. Eukaryotic translation initiation factors eIF4G (gene and protein) and eIF4E (protein) were also upregulated by daidzein. The eIF4F complex (eIF4G, $\mathrm{E}, \mathrm{A}, \mathrm{B})$, that scans the $5^{\prime} \mathrm{UTR}$ and unwinds mRNA secondary structure to expose the start codon for translation initiation, has been shown to specifically regulate the expression of mRNAs with long, highly structured UTRs. The eIF4F complex members have been shown to be overexpressed in advanced cancer and to be essential for translation of a subset of proteins that regulate cellular bioenergetics, survival, and proliferation [70-72]. Our results show that translational regulation may be a mechanism by which daidzein exerts differential effects on cancer progression because a number of proteins were elevated in the mammary tumors following daidzein including survivin, an inhibitor of apoptosis implicated with cancer malignancy that has been shown to be sensitive to eIF4E levels [51, 52, 73]. Recent studies have associated increased survivin expression with cancer malignancy [73]. As shown by a previous study, where reduced survivin levels by combined genistein and tamoxifen was attributed to apoptosis in breast cancer cells [30], our data show reduced survivin levels in mammary tumors in response to genistein diets. Since increased survivin levels are expected to reduce caspase activity and thus, apoptosis, differential expression of survivin in tumors following daidzein or genistein diets may contribute to the disparate effects of genistein and daidzein on tumor growth and metastasis.

Dietary daidzein also increased IRS1 levels in tumors suggesting that insulin-like growth factor receptor (IGFR) signaling may be involved with increased breast cancer progression by daidzein. Statistically significant IRAKI upregulation by both genistein $(P<0.006)$ and daidzein $(P<0.001)$ may indicate a soy isoflavone mediated activation of Nf- $\kappa \mathrm{B}$ and MAPK signaling. However, since IRAK1 needs to be ubiquitinated to be active, increased IRAK1 expression may not necessarily result in enhanced NF- $\kappa$ B activity [74]. Similarly, upregulation of GSK3B gene expression by daidzein is not indicative of upregulation of its activity, which is downregulated by Akt signaling [75]. Future studies will determine whether expression of these genes in response to dietary daidzein results in enhanced protein expression and activity that contribute to cancer malignancy.

Combined soy isoflavones that significantly increased metastasis did not affect Rho GTPase expression but significantly increased eIF4E levels. Therefore, this study indicates that modulation of protein synthesis may be a novel mechanism of regulation for cancer metastasis. Since soy isoflavones did not change primary tumor size and a number of genes that were regulated by genistein or daidzein were up- or down-regulated by the combination diet in a parallel but statistically non-significant manner, it is possible that the effects of genistein and daidzein were neutralized in the primary tumors by the combined soy isoflavones treatment. Our results suggest that the increase in distant metastasis by combined soy isoflavones occurs via activation of molecular mechanism(s) independent of the PI3-K pathway. It is possible that the presence of glycitein, albeit at a much smaller concentration, could have contributed to a combinatorial effect on metastasis. A recent study reported that glycitein may act similar to genistein by increasing apoptosis via reduction of the Bcl-2/Bax ratio [10]. Future experiments will delineate the specific effects of glycitein as well as the molecular mechanisms that regulate cancer metastasis following dietary soy isoflavones. 
This study indicates that consumption of soy products may have differential and complex effects on breast cancer progression and metastasis to different organs. Recent studies have shown that while dietary soy isoflavones do not affect breast cancer, they may increase the risk of colorectal cancer among women and prostate cancer among men [76]. Others have shown that soy food consumption was significantly associated with decreased risk of death and recurrence for breast cancer [77]. Thus, this investigation is of considerable interest in the debate about whether soy isoflavones promote or prevent breast cancer, particularly the perils of using soy in women diagnosed with breast cancer or those at high risk. However, caution must be exercised with interpretation of our results, since this study represents the effect of a single concentration of soy isoflavones that reflect a high soy diet conducted with an ER negative cancer cell line in non-ovariectomized nude mice.

Acknowledgements This study was supported by AICR IIG 03-3106 and NIH/NIGMS SC3GM084824 to SD and NIH/NCCR G12RR003035 and NIH/NIGMS S06GM050695 to UCC. We thank Alexander Schlachterman for assistance with animal protocols and Kristin M. Wall for image analysis.

Open Access This article is distributed under the terms of the Creative Commons Attribution Noncommercial License which permits any noncommercial use, distribution, and reproduction in any medium, provided the original author(s) and source are credited.

\section{References}

1. Jemal A, Murray T, Ward E, Samuels A, Tiwari RC, Ghafoor A, Feuer EJ, Thun MJ (2008) Cancer statistics, 2008. CA Cancer J Clin 5:71-96

2. Messina M, Caskill-Stevens W, Lampe JW (2006) Addressing the soy and breast cancer relationship: review, commentary, and workshop proceedings. J Natl Cancer Inst 98:1275-1284

3. Murkies AL, Teede HJ, Davis SR (2000) What is the role of phytoestrogens in treating menopausal symptoms? Med J Aust 173(Suppl):S97-S98

4. Lampe JW, Nishino Y, Ray RM, Wu C, Li W, Lin MG, Gao DL, $\mathrm{Hu}$ Y, Shannon J, Stalsberg H, Porter PL, Frankenfeld CL, Wahala K, Thomas DB (2007) Plasma isoflavones and fibrocystic breast conditions and breast cancer among women in Shanghai, China. Cancer Epidemiol Biomarkers Prev 16:2579-2586

5. Kumar N, Allen K, Riccardi D, Kazi A, Heine J (2004) Isoflavones in breast cancer chemoprevention: where do we go from here? Front Biosci 9:2927-2934

6. Rice S, Whitehead SA (2006) Phytoestrogens and breast cancerpromoters or protectors? Endocr Relat Cancer 13:995-1015

7. Vincent A, Fitzpatrick LA (2000) Soy isoflavones: are they useful in menopause? Mayo Clin Proc 75:1174-1184

8. Murphy PA, Song T, Buseman G, Barua K, Beecher GR, Trainer $\mathrm{D}$, Holden J (1999) Isoflavones in retail and institutional soy foods. J Agric Food Chem 47:2697-2704
9. Chrzan BG, Bradford PG (2007) Phytoestrogens activate estrogen receptor beta 1 and estrogenic responses in human breast and bone cancer cell lines. Mol Nutr Food Res 51:171-177

10. Sakamoto T, Horiguchi H, Oguma E, Kayama F (2009) Effects of diverse dietary phytoestrogens on cell growth, cell cycle and apoptosis in estrogen-receptor-positive breast cancer cells. J Nutr Biochem. doi:10.1016/j.jnutbio.2009.06.010

11. Shao ZM, Wu J, Shen ZZ, Barsky SH (1998) Genistein inhibits both constitutive and EGF-stimulated invasion in ER-negative human breast carcinoma cell lines. Anticancer Res 18:1435-1439

12. Shao ZM, Wu J, Shen ZZ, Barsky SH (1998) Genistein exerts multiple suppressive effects on human breast carcinoma cells. Cancer Res 58:4851-4857

13. Li Y, Bhuiyan M, Sarkar FH (1999) Induction of apoptosis and inhibition of c-erbB-2 in MDA-MB-435 cells by genistein. Int $\mathrm{J}$ Oncol 15:525-533

14. Lamartiniere CA, Murrill WB, Manzolillo PA, Zhang JX, Barnes S, Zhang X, Wei H, Brown NM (1998) Genistein alters the ontogeny of mammary gland development and protects against chemically-induced mammary cancer in rats. Proc Soc Exp Biol Med 217:358-364

15. Whitsett TG Jr, Lamartiniere CA (2006) Genistein and resveratrol: mammary cancer chemoprevention and mechanisms of action in the rat. Expert Rev Anticancer Ther 6:1699-1706

16. Vantyghem SA, Wilson SM, Postenka CO, Al-Katib W, Tuck $\mathrm{AB}$, Chambers AF (2005) Dietary genistein reduces metastasis in a postsurgical orthotopic breast cancer model. Cancer Res 65:3396-3403

17. Singh AV, Franke AA, Blackburn GL, Zhou JR (2006) Soy phytochemicals prevent orthotopic growth and metastasis of bladder cancer in mice by alterations of cancer cell proliferation and apoptosis and tumor angiogenesis. Cancer Res 66:1851-1858

18. Magee PJ, McGlynn H, Rowland IR (2004) Differential effects of isoflavones and lignans on invasiveness of MDA-MB-231 breast cancer cells in vitro. Cancer Lett 20:835-841

19. Farina HG, Pomies M, Alonso DF, Gomez DE (2006) Antitumor and antiangiogenic activity of soy isoflavone genistein in mouse models of melanoma and breast cancer. Oncol Rep 16:885-891

20. Allred CD, Allred KF, Ju YH, Virant SM, Helferich WG (2001) Soy diets containing varying amounts of genistein stimulate growth of estrogen-dependent (MCF-7) tumors in a dose-dependent manner. Cancer Res 61:5045-5050

21. El Touny LH, Banerjee PP (2009) Identification of a biphasic role for genistein in the regulation of prostate cancer growth and metastasis. Cancer Res 69:3695-3703

22. Jeng YJ, Watson CS (2009) Proliferative and anti-proliferative effects of dietary levels of phytoestrogens in rat pituitary GH3/ B6/F10 cells - the involvement of rapidly activated kinases and caspases. BMC Cancer 9:334

23. Shon YH, Park SD, Nam KS (2006) Effective chemopreventive activity of genistein against human breast cancer cells. J Biochem Mol Biol 39:448-451

24. Kousidou OC, Tzanakakis GN, Karamanos NK (2006) Effects of the natural isoflavonoid genistein on growth, signaling pathways and gene expression of matrix macromolecules by breast cancer cells. Mini Rev Med Chem 6:331-337

25. Rabiau N, Kossai M, Braud M, Chalabi N, Satih S, Bignon YJ, Bernard-Gallon DJ (2010) Genistein and daidzein act on a panel of genes implicated in cell cycle and angiogenesis by Polymerase Chain Reaction arrays in human prostate cancer cell lines. Cancer Epidemiol 34:200-206

26. Huang X, Chen S, Xu L, Liu Y, Deb DK, Platanias LC, Bergan RC (2005) Genistein inhibits p38 map kinase activation, matrix metalloproteinase type 2 , and cell invasion in human prostate epithelial cells. Cancer Res 65:3470-3478 
27. Brownson DM, Azios NG, Fuqua BK, Dharmawardhane SF, Mabry TJ (2002) Flavonoid effects relevant to cancer. J Nutr 132:3482S-3489S

28. Guo Y, Wang S, Hoot DR, Clinton SK (2007) Suppression of VEGF-mediated autocrine and paracrine interactions between prostate cancer cells and vascular endothelial cells by soy isoflavones. J Nutr Biochem 18:408-417

29. Vanden BW, Dijsselbloem N, Vermeulen L, Ndlovu N, Boone E, Haegeman G (2006) Attenuation of mitogen- and stress-activated protein kinase-1-driven nuclear factor-kappaB gene expression by soy isoflavones does not require estrogenic activity. Cancer Res 66:4852-4862

30. Mai Z, Blackburn GL, Zhou JR (2007) Genistein sensitizes inhibitory effect of tamoxifen on the growth of estrogen receptorpositive and HER2-overexpressing human breast cancer cells. Mol Carcinog 46:534-542

31. Fang MZ, Chen D, Sun Y, Jin Z, Christman JK, Yang CS (2005) Reversal of hypermethylation and reactivation of p16INK4a, RARbeta, and MGMT genes by genistein and other isoflavones from soy. Clin Cancer Res 11:7033-7041

32. Su Y, Simmen FA, Xiao R, Simmen RC (2007) Expression profiling of rat mammary epithelial cells reveals candidate signaling pathways in dietary protection from mammary tumors. Physiol Genomics 30:8-16

33. Lakshman M, Xu L, Ananthanarayanan V, Cooper J, Takimoto CH, Helenowski I, Pelling JC, Bergan RC (2008) Dietary genistein inhibits metastasis of human prostate cancer in mice. Cancer Res 68:2024-2032

34. Jin S, Zhang QY, Kang XM, Wang JX, Zhao WH (2010) Daidzein induces MCF-7 breast cancer cell apoptosis via the mitochondrial pathway. Ann Oncol 21:263-268

35. Chambers AF (2009) Influence of diet on metastasis and tumor dormancy. Clin Exp Metastasis 26:61-66

36. Lacroix M (2009) MDA-MB-435 cells are from melanoma, not from breast cancer. Cancer Chemother Pharmacol 63:567

37. Chambers AF (2009) MDA-MB-435 and M14 cell lines: identical but not M14 melanoma? Cancer Res 69:5292-5293

38. Sellappan S, Grijalva R, Zhou X, Yang W, Eli MB, Mills GB, Yu D (2004) Lineage infidelity of MDA-MB-435 cells: expression of melanocyte proteins in a breast cancer cell line. Cancer Res 64:3479-3485

39. Phadke PA, Mercer RR, Harms JF, Jia Y, Frost AR, Jewell JL, Bussard KM, Nelson S, Moore C, Kappes JC, Gay CV, Mastro AM, Welch DR (2006) Kinetics of metastatic breast cancer cell trafficking in bone. Clin Cancer Res 12:1431-1440

40. Price JE, Zhang RD (1990) Studies of human breast cancer metastasis using nude mice. Cancer Metastasis Rev 8:285-297

41. Harms JF, Welch DR (2003) MDA-MB-435 human breast carcinoma metastasis to bone. Clin Exp Metastasis 20:327334

42. Schlachterman A, Valle F, Wall KM, Azios NG, Castillo L, Morell L, Washington AV, Cubano LA, Dharmawardhane SF (2008) Combined resveratrol, quercetin, and catechin treatment reduces breast tumor growth in a nude mouse model. Transl Oncol 1:19-27

43. Castillo-Pichardo L, Martinez-Montemayor MM, Martinez JE, Wall KM, Cubano LA, Dharmawardhane S (2009) Inhibition of mammary tumor growth and metastases to bone and liver by dietary grape polyphenols. Clin Exp Metastasis 26:505-516

44. Carlson AL, Hoffmeyer MR, Wall KM, Baugher PJ, RichardsKortum R, Dharmawardhane SF (2006) In situ analysis of breast cancer progression in murine models using a macroscopic fluorescence imaging system. Lasers Surg Med 38:928-938

45. Wu A, Yu MC, Tseng CC, Pike MC (2008) Epidemiology of soy exposures and breast cancer risk. Br J Cancer 98:9-14
46. Li D, Yee JA, McGuire MH, Murphy PA, Yan L (1999) Soybean isoflavones reduce experimental metastasis in mice. $\mathrm{J}$ Nutr 129: $1075-1078$

47. Iishi H, Tatsuta M, Baba M, Yano H, Sakai N, Akedo H (2000) Genistein attenuates peritoneal metastasis of azoxymethaneinduced intestinal adenocarcinomas in Wistar rats. Int $\mathrm{J}$ Cancer $86: 416-420$

48. Gallo D, Ferlini C, Fabrizi M, Prislei S, Scambia G (2006) Lack of stimulatory activity of a phytoestrogen-containing soy extract on the growth of breast cancer tumors in mice. Carcinogenesis 27:1404-1409

49. Stephens L, Williams R, Hawkins P (2005) Phosphoinositide 3kinases as drug targets in cancer. Curr Opin Pharmacol 5:357365

50. Manning BD, Cantley LC (2007) AKT/PKB signaling: navigating downstream. Cell 129:1261-1274

51. Graff JR, Konicek BW, Carter JH, Marcusson EG (2008) Targeting the eukaryotic translation initiation factor $4 \mathrm{E}$ for cancer therapy. Cancer Res 68:631-634

52. Graff JR, Konicek BW, Vincent TM, Lynch RL, Monteith D, Weir SN, Schwier P, Capen A, Goode RL, Dowless MS, Chen Y, Zhang H, Sissons S, Cox K, McNulty AM, Parsons SH, Wang T, Sams L, Geeganage S, Douglass LE, Neubauer BL, Dean NM, Blanchard K, Shou J, Stancato LF, Carter JH, Marcusson EG (2007) Therapeutic suppression of translation initiation factor eIF4E expression reduces tumor growth without toxicity. J Clin Invest 117:2638-2648

53. Nachmias B, Ashhab Y, Ben-Yehuda D (2004) The inhibitor of apoptosis protein family (IAPs): an emerging therapeutic target in cancer. Semin Cancer Biol 14:231-243

54. Bussard KM, Gay CV, Mastro AM (2008) The bone microenvironment in metastasis; what is special about bone? Cancer Metastasis Rev 27:41-55

55. Rowland I, Faughnan M, Hoey L, Wahala K, Williamson G, Cassidy A (2003) Bioavailability of phyto-oestrogens. Br J Nutr 89 Suppl 1:S45-S58

56. Zhou S, Hu Y, Zhang B, Teng Z, Gan H, Yang Z, Wang Q, Huan M, Mei Q (2008) Dose-dependent absorption, metabolism, and excretion of genistein in rats. J Agric Food Chem 56:8354-8359

57. Franke AA, Ashburn LA, Kakazu K, Suzuki S, Wilkens LR, Halm BM (2009) Apparent bioavailability of isoflavones after intake of liquid and solid soya foods. Br J Nutr 102:1203-1210

58. Mai Z, Blackburn GL, Zhou JR (2007) Soy phytochemicals synergistically enhance the preventive effect of tamoxifen on the growth of estrogen-dependent human breast carcinoma in mice. Carcinogenesis 28:1217-1223

59. Ju YH, Fultz J, Allred KF, Doerge DR, Helferich WG (2006) Effects of dietary daidzein and its metabolite, equol, at physiological concentrations on the growth of estrogen-dependent human breast cancer (MCF-7) tumors implanted in ovariectomized athymic mice. Carcinogenesis 27:856-863

60. Santell RC, Kieu N, Helferich WG (2000) Genistein inhibits growth of estrogen-independent human breast cancer cells in culture but not in athymic mice. J Nutr 130:1665-1669

61. Sakla MS, Shenouda NS, Ansell PJ, Macdonald RS, Lubahn DB (2007) Genistein affects HER2 protein concentration, activation, and promoter regulation in BT-474 human breast cancer cells. Endocrine 32:69-78

62. Azios NG, Dharmawardhane S (2005) Role of phytoestrogens in modulating focal adhesions and focal adhesion kinase (FAK) activity in breast cancer cells. In: Li J, Li SA, Llombart-Bosch A (eds) Hormonal carcinogenesis. Springer-Verlag, NY, pp 300307

63. Fonseca D, Ward WE (2006) Detection of isoflavones in mouse tibia after feeding daidzein. J Med Food 9:436-439 
64. Vega FM, Ridley AJ (2008) Rho GTPases in cancer cell biology. FEBS Lett 582:2093-2101

65. Vadlamudi RK, Kumar R (2004) p21-activated kinase 1: an emerging therapeutic target. Cancer Treat Res 119:77-88

66. Ridley AJ, Hall A (1994) Signal transduction pathways regulating Rho-mediated stress fibre formation: requirement for a tyrosine kinase. EMBO J 13:2600-2610

67. Lavigne JA, Takahashi Y, Chandramouli GV, Liu H, Perkins SN, Hursting SD, Wang TT (2007) Concentration-dependent effects of genistein on global gene expression in MCF-7 breast cancer cells: an oligo microarray study. Breast Cancer Res Treat 110:85-98

68. Clark JW, Santos-Moore A, Stevenson LE, Frackelton AR Jr (1996) Effects of tyrosine kinase inhibitors on the proliferation of human breast cancer cell lines and proteins important in the ras signaling pathway. Int J Cancer 65:186-191

69. Bosco EE, Mulloy JC, Zheng Y (2009) Rac1 GTPase: a "Rac" of all trades. Cell Mol Life Sci 66:370-374

70. Silvera D, Arju R, Darvishian F, Levine PH, Zolfaghari L, Goldberg J, Hochman T, Formenti SC, Schneider RJ (2009) Essential role for eIF4GI overexpression in the pathogenesis of inflammatory breast cancer. Nat Cell Biol 11:903-908

71. Braunstein S, Karpisheva K, Pola C, Goldberg J, Hochman T, Yee H, Cangiarella J, Arju R, Formenti SC, Schneider RJ (2007)
A hypoxia-controlled cap-dependent to cap-independent translation switch in breast cancer. Mol Cell 28:501-512

72. Ramirez-Valle F, Braunstein S, Zavadil J, Formenti SC, Schneider RJ (2008) eIF4GI links nutrient sensing by mTOR to cell proliferation and inhibition of autophagy. J Cell Biol 181:293-307

73. Krepela E, Dankova P, Moravcikova E, Krepelova A, Prochazka J, Cermak J, Schutzner J, Zatloukal P, Benkova K (2009) Increased expression of inhibitor of apoptosis proteins, survivin and XIAP, in non-small cell lung carcinoma. Int J Oncol 35:1449-1462

74. Conze DB, Wu CJ, Thomas JA, Landstrom A, Ashwell JD (2008) Lys63-linked polyubiquitination of IRAK-1 is required for interleukin-1 receptor- and toll-like receptor-mediated NF-kappaB activation. Mol Cell Biol 28:3538-3547

75. Lizcano JM, Alessi DR (2002) The insulin signalling pathway. Curr Biol 12:R236-R238

76. Ward HA, Kuhnle GG, Mulligan AA, Lentjes MA, Luben RN, Khaw KT (2010) Breast, colorectal, and prostate cancer risk in the European Prospective Investigation into Cancer and Nutrition-Norfolk in relation to phytoestrogen intake derived from an improved database. Am J Clin Nutr 91:440-448

77. Shu XO, Zheng Y, Cai H, Gu K, Chen Z, Zheng W, Lu W (2009) Soy food intake and breast cancer survival. JAMA 302:2437-2443 